\title{
Reclassification of Brevibacterium liquefaciens Okabayashi and Masuo 1960 as Arthrobacter nicotianae Giovannozzi-Sermanni 1959
}

\author{
Roberto Gelsomino, Marc Vancanneyt and Jean Swings \\ BCCM/LMG Bacteria Collection, Laboratorium voor Microbiologie, Universiteit Gent, \\ Ledeganckstraat 35, Gent, Belgium
}

Correspondence

Roberto Gelsomino

roberto.gelsomino@ugent.be

\begin{abstract}
Brevibacterium liquefaciens ATCC $14929^{\top}$ was reclassified as Corynebacterium liquefaciens by Lanéelle et al. (1980). A further study by Stackebrandt et al. (1983) described the same strain, indicating high genomic and chemotaxonomic relatedness to Arthrobacter nicotianae; however, reclassification was not formally proposed. Because of the discrepancies between their previous work and the data of Collins \& Kroppenstedt (1983), Lanéelle and colleagues re-examined $B$. liquefaciens and withdrew their recommendation for the assignment of $B$. liquefaciens to the genus Corynebacterium (Lanéelle et al., 1984). Formal reclassification of $B$. liquefaciens as A. nicotianae is now proposed.
\end{abstract}

Brevibacterium liquefaciens Okabayashi \& Masuo 1960 ATCC $14929^{\mathrm{T}}\left(=\right.$ DSM $20579^{\mathrm{T}}=\mathrm{NCIMB} \quad 9545^{\mathrm{T}}=\mathrm{LMG}$ $16159^{\mathrm{T}}$; Skerman et al., 1980) was combined with Corynebacterium liquefaciens by Lanéelle et al. (1980), with ATCC $14929^{\mathrm{T}}$ as the type strain, on the basis of shared physiological, cell wall and lipid attributes and DNA-DNA homology with Corynebacterium diphtheriae PW8. However, the results of Lanéelle et al. (1980) did not agree with those obtained by Collins \& Kroppenstedt (1983), who showed that the lipid composition of C. liquefaciens NCIMB $9545^{\mathrm{T}}$ was quite different from that of C. diphtheriae; nor did they agree with the data of Stackebrandt et al. (1983). These authors determined the DNA G $+C$ contents of and carried out DNA-DNA hybridization studies on Arthrobacter nicotianae DSM $20123^{\mathrm{T}}\left(=\mathrm{NCIMB} 9458^{\mathrm{T}}\right)$ and $C$. liquefaciens DSM $20579^{\mathrm{T}}$, and provided data that were sufficient to suggest that $C$. liquefaciens should be combined with A. nicotianae. Although they were surprised to find that strain ATCC $14929^{\mathrm{T}}$ showed such high similarity to A. nicotianae, Stackebrandt et al. (1983) did not formally propose any union of A. nicotianae and C. liquefaciens, as the identity of strains of $C$. liquefaciens (B. liquefaciens) that were deposited in various culture collections had not been confirmed. At this point, it may be interesting to note that the Deutsche Sammlung von Mikroorganismen und Zellkulturen (DSMZ, Braunschweig, Germany) obtained $B$. liquefaciens DSM $20579^{\mathrm{T}}$ from the National Collection of Industrial and Marine Bacteria (NCIMB 9545 ${ }^{\mathrm{T}}$; Aberdeen, Scotland, UK), where it is deposited as B. liquefaciens. NCIMB, in turn, obtained their strain from the American Type Culture Collection (ATCC $14929^{\mathrm{T}}$; Manassas, VA, USA), where it is deposited as C. liquefaciens.

Because of the differences between their data and those of other workers, Lanéelle et al. (1984) re-examined strain ATCC $14929^{\mathrm{T}}$. The results they obtained disagreed with those of Lanéelle et al. (1980), but agreed with those of Collins \& Kroppenstedt (1983). Consequently, Lanéelle et al. (1984) withdrew their recommendation for the assignment of $B$. liquefaciens to the genus Corynebacterium, assuming the mislabelling of strain ATCC $14929^{\mathrm{T}}$ in one of the laboratories that were responsible for the work.

Moreover, both Bergey's Manual of Systematic Bacteriology (Jones \& Keddie, 1986; Keddie et al., 1986) and the DSMZ still consider B. liquefaciens to be A. nicotianae, even though no official renaming has occurred.

In this paper, we propose that $B$. liquefaciens ATCC $14929^{\mathrm{T}}$ should be assigned to A. nicotianae based on: (i) $98 \cdot 8 \%$ $16 \mathrm{~S}$ rDNA sequence similarity between $B$. liquefaciens DSM $20579^{\mathrm{T}}$ and A. nicotianae DSM $20123^{\mathrm{T}}$ (our confirmation; GenBank accession numbers AJ251417 and X80739, respectively); (ii) similar menaquinone profiles (Collins \& Kroppenstedt, 1983); (iii) identical chromatographic mobility of glycolipids (Collins \& Kroppenstedt, 1983); (iv) identical polar lipid patterns for A. nicotianae and B. liquefaciens (Collins \& Kroppenstedt, 1983); and (v) the same peptidoglycan variation (A4 $\alpha)$ (Stackebrandt et al., 1984). Furthermore, the DNA G $+C$ content of B. liquefaciens $(63.2 \%)$ fits the range of DNA G + C contents for the genus Arthrobacter sensu stricto (59-66 mol\%) (Stackebrandt et al., 1983). SDS-PAGE was carried out in our laboratory on B. liquefaciens LMG $16159^{\mathrm{T}}$ [obtained from the Japan Collection of Microorganisms, RIKEN, Japan (JCM $1970^{\mathrm{T}}$ ), who, in turn, obtained their strain from the ATCC (ATCC $14929^{\mathrm{T}}$ )] and it was identified as A. nicotianae. SDS-PAGE profiling of whole-cell proteins 
provides valuable information on the similarity of bacteria at the species and subspecies levels (Vandamme et al., 1996). Finally, the earlier DNA-DNA hybridization data of Stackebrandt et al. (1983) clearly show high relatedness (90\% similarity) between B. liquefaciens and A. nicotianae.

\section{Acknowledgements}

The authors wish to acknowledge the European Community's project Smear Cheese Microflora 'QLK1-CT-2001-02228'.

\section{References}

Collins, M. D. \& Kroppenstedt, R. M. (1983). Lipid composition as a guide to the classification of some coryneform bacteria containing an A4 $\alpha$ type peptidoglycan (Schleifer and Kandler). Syst Appl Microbiol 4, 95-104.

Giovannozzi-Sermanni, G. (1959). Una nuova species di Arthrobacter determinante la degradazione della nicotina: Arthrobacter nicotianae. Il Tabacco 63, 83-86 (in Italian).

Jones, D. \& Keddie, R. M. (1986). Genus Brevibacterium Breed 1953, $13^{\mathrm{AL}}$ emend. Collins et al. 1980, 6. In Bergey's Manual of Systematic Bacteriology, vol. 2, pp. 1301-1313. Edited by P. H. A. Sneath, N. S. Mair, M. E. Sharpe \& J. G. Holt. Baltimore: Williams \& Wilkins.

Keddie, R. M., Collins, M. D. \& Jones, D. (1986). Genus Arthrobacter Conn and Dimmick 1947, 300 ${ }^{\mathrm{AL}}$. In Bergey's Manual of Systematic Bacteriology, vol. 2, pp. 1288-1301. Edited by P. H. A. Sneath, N. S. Mair, M. E. Sharpe \& J. G. Holt. Baltimore: Williams \& Wilkins.
Lanéelle, M.-A., Asselineau, J., Welby, M., Norgard, M. V., Imaeda, T., Pollice, M. C. \& Barksdale, L. (1980). Biological and chemical bases for the reclassification of Brevibacterium vitarumen (Bechdel et al.) Breed (Approved Lists, 1980) as Corynebacterium vitarumen (Bechdel et al.) comb. nov. and Brevibacterium liquefaciens Okabayashi and Masuo (Approved Lists, 1980) as Corynebacterium liquefaciens (Okabayashi and Masuo) comb. nov. Int J Syst Bacteriol 30, 539-546.

Lanéelle, M.-A., Asselineau, J., Welby, M., Norgard, M. V., Imaeda, T., Pollice, M. C. \& Barksdale, L. (1984). AUTHOR'S CORRECTION. Biological and chemical bases for the reclassification of Brevibacterium vitarumen (Bechdel et al.) Breed (Approved Lists, 1980) as Corynebacterium vitarumen (Bechdel et al.) comb. nov. and Brevibacterium liquefaciens Okabayashi and Masuo (Approved Lists, 1980) as Corynebacterium liquefaciens (Okabayashi and Masuo) comb. nov. Int J Syst Bacteriol 34, 274.

Okabayashi, T. \& Masuo, E. (1960). Occurrence of nucleotides in the culture fluid of microorganisms. II. The nucleotides in the broth of Brevibacterium liquefaciens novo sp. Chem Pharm Bull (Tokyo) 8, 1089-1094.

Skerman, V. B. D., McGowan, V. \& Sneath, P. H. A. (1980). Approved lists of bacterial names. Int J Syst Bacteriol 30, 225-420.

Stackebrandt, E., Fowler, V. J., Fiedler, F. \& Seiler, H. (1983). Taxonomic studies on Arthrobacter nicotianae and related taxa: description of Arthrobacter uratoxydans sp. nov. and Arthrobacter sulfureus sp. nov. and reclassification of Brevibacterium protophormiae as Arthrobacter protophormiae comb. nov. Syst Appl Microbiol 4, 470-486.

Vandamme, P., Pot, B., Gillis, M., De Vos, P., Kersters, K. \& Swings, J. (1996). Polyphasic taxonomy, a consensus approach to bacterial systematics. Microbiol Rev 60, 407-438. 